OPEN ACCESS

Edited by:

Diane Cooper,

University of the Western Cape,

South Africa

Reviewed by:

Tarun Stephen Weeramanthri, Government of Western Australia Department of Health, Australia

Hanani Tabana,

University of the Western Cape,

South Africa

Lucia Knight,

University of the Western Cape,

South Africa

*Correspondence:

Nildah Lambo

nlambo@hotmail.com

Specialty section:

This article was submitted to Public Health Policy, a section of the journal

Frontiers in Public Health

Received: 09 August 2016 Accepted: 20 January 2017 Published: 09 February 2017

Citation:

Jacobs C, Moshabela M, Maswenyeho S, Lambo N and Michelo C (2017) Predictors of

Antenatal Care, Skilled Birth Attendance, and Postnatal Care Utilization among the Remote and

Poorest Rural Communities of Zambia: A Multilevel Analysis.

Front. Public Health 5:11. doi: 10.3389/fpubh.2017.00011

\section{Predictors of Antenatal Care, Skilled Birth Attendance, and Postnatal Care Utilization among the Remote and Poorest Rural Communities of Zambia: A Multilevel Analysis}

\author{
Choolwe Jacobs ${ }^{1,2}$, Mosa Moshabela ${ }^{1,3}$, Sitali Maswenyeho ${ }^{4}$, Nildah Lambo $^{4 *}$ and \\ Charles Michelo ${ }^{2}$
}

${ }^{1}$ School of Nursing and Public Health, University of KwaZulu-Natal, Durban, South Africa, ${ }^{2}$ Department of Public Health, School of Medicine, University of Zambia, Lusaka, Zambia, ${ }^{3}$ Africa Centre for Population Health, Mtubatuba, South Africa, ${ }^{4}$ UNICEF, Lusaka, Zambia

Objective: Optimal utilization of maternal health-care services is associated with reduction of mortality and morbidity for both mothers and their neonates. However, deficiencies and disparity in the use of key maternal health services within most developing countries still persist. We examined patterns and predictors associated with the utilization of specific indicators for maternal health services among mothers living in the poorest and remote district populations of Zambia.

Methods: A cross-sectional baseline household survey was conducted in May 2012. A total of 551 mothers with children between the ages 0 and 5 months were sampled from 29 catchment areas in four rural and remote districts of Zambia using the lot quality assurance sampling method. Using multilevel modeling, we accounted for individualand community-level factors associated with utilization of maternal health-care services, with a focus on antenatal care (ANC), skilled birth attendance (SBA), and postnatal care (PNC).

Results: Utilization rates of focused ANC, SBA, and PNC within $48 \mathrm{~h}$ were 30,37 , and $28 \%$, respectively. The mother's ability to take an HIV test and receiving test results and uptake of intermittent preventive treatment for malaria were positive predictors of focused ANC. Receiving ANC at least once from skilled personnel was a significant predictor of SBA and PNC within $48 \mathrm{~h}$ after delivery. Women who live in centralized rural areas were more likely to use SBA than those living in remote rural areas.

Conclusion: Utilization of maternal health services by mothers living among the remote and poor marginalized populations of Zambia is much lower than the national averages. Finding that women that receive ANC once from a skilled attendant among the

Abbreviations: ANC, antenatal care; SBA, skilled birth attendance; PNC, postnatal care; IPTp, intermittent preventive treatment; HIV, human immunodeficiency syndrome; LQAS, lot quality assurance sampling; PHC, primary health care; WHO, World Health Organization. 
remote and poorest populations are more likely to have a SBA and PNC, suggests the importance of contact with a skilled health worker even if it is just once, in influencing use of services. Therefore, it appears that in order for women in these marginalized communities to benefit from SBA and PNC, it is important for them to have at least one ANC provided by a skilled personnel, rather than non-skilled health-care providers.

Keywords: antenatal care, focused antenatal care, skilled birth attendance, postnatal care, maternal health-care utilization

\section{INTRODUCTION}

Poor utilization of maternal health services is frequently associated with maternal deaths and morbidity (1), and yet, most maternal deaths could be prevented if all women successfully utilized maternal health-care services (2). Literature also shows that utilization of maternal and neonatal health $(\mathrm{MNH})$ services can be successfully traced through key services such as attendance of antenatal care (ANC), birth by a skilled health worker, and postnatal care (PNC), all of which are evidently associated with reduction in mortality and morbidity for mothers and their neonates (2-4). According to the World Health Organization's (WHO) recommendation, every pregnant woman should receive a minimum of four ANC visits in low-risk pregnancies, also known as focused ANC. Focused ANC may be particularly advantageous in resource-limited and marginalized communities, as it requires a minimum of four visits, which are more practical than the traditional ANC (5).

Skilled birth attendance (SBA) is defined as the process by which a woman is provided with adequate care during labor, delivery, and the early postpartum period by a skilled health worker such as a doctor, nurse, or midwife (6). SBA is important for the early identification of signs of complications in order to institute timely management, including referrals to higher levels of care where necessary. In addition, utilization of PNC within $48 \mathrm{~h}$ of delivery is known to improve health outcomes for both the mother and the neonate by reducing morbidity and mortality (7). However, despite these essential services being available in health facilities and being made affordable in most developing countries, utilization of ANC, SBA, and PNC remain limited, particularly in developing countries (8). For instance, less than $30 \%$ of women are said to access and use PNC services in developing countries (9). The rural populations are the most affected (10). In Zambia, like many other developing countries, utilization of maternal health in rural areas is a challenge. According to the Zambia Demographic Health Survey (ZDHS), only 55\% of women attend the WHO-recommended focused ANC visits, $56 \%$ are assisted by a skilled birth attendant, and only $54 \%$ attend PNC visits (11).

Studies to identify and understand reasons for poor utilization of maternal health-care services among rural populations in developing countries, indicate that patterns of utilizing indicators of maternal health services (ANC, SBA, and PNC) differ across socio demographic, socioeconomic, and cultural context (10, $12-16)$, including accessibility of these services $(2,17,18)$. Factors that influence utilization of maternal health services in rural areas have also been shown to operate at various levels; individual, household, and community $(10,12,13)$. According to Jat et al. (12), both individual- and community-level characteristics can cause disparities in the patterns of maternal health-care utilization among rural populations. However, there is lack of evidence on the utilization patterns and predictors of maternal health services among the remote and poorest populations of Zambia. The remote and poorest populations are the most vulnerable and marginalized communities of Zambia. The classification of poorest is based on the analysis of national data on the population distribution of vulnerability, poverty, and deprivation (19). The poorest inhabit households that live on less than a dollar per day (20). Remoteness is determined on the basis of distance from cities and towns, as well as geographical disadvantages, such as being hard to reach, poor road network, poor transportation access, long travel time, and resource-limitations to amenable social services.

Although several studies have been conducted to identify and understand reasons for poor utilization of maternal health-care services in the rural areas $(1,2,12,17,21,22)$, studies trying to examine predictors of utilization of the three indicators of pregnancy-related care-antenatal, delivery, and postnatal services-among the remote and poorest rural populations in Zambia in particular are very scarce.

In addition, although, we know that in Zambia, utilization of maternal health services in rural areas is low (11), we do not know the patterns and drivers of utilization of maternal health services in the most remote and poorest rural populations.

Furthermore, we do not know if there are possible existing disparities in the use of the key maternal health-care indicators among these populations. Thus, identifying utilization patterns and the associated factors for the specific indicators of maternal health services is crucial in informing policy and implementation. Therefore, the objective of this study was to examine patterns and predictors of utilization of the three indicators of maternal health-care services among mothers living in the poorest rural and remote populations of Zambia.

\section{MATERIALS AND METHODS}

\section{Study Setting}

The study was conducted in four rural districts namely Mungwi, Luwingu Samfya, and Chiengi, located in Luapula and the Northern provinces of Zambia. These districts are classified among the 13 poorest in Zambia, where the most vulnerable and marginalized people live. The classification is based on the national distribution of vulnerability, poverty, and deprivation (20). 
The sampled districts have the highest maternal and child mortality rates (11). The combined estimated population size of these four districts is 580,090 (20). Most of the people in these four districts are peasant farmers, engaged in crop, livestock production, and fishing.

\section{Study Design and Sampling}

The study was a cross-sectional household survey based on the lot quality assurance sampling (LQAS) method. LQAS was used as guided by the WHO and other related studies (23). Using the LQAS method, a district is considered an independent site, and sub-divided into community clusters regarded as supervisory areas. A supervisory area or community cluster constitutes a catchment area with a dedicated health facility responsible for delivering health services. In this study, the four selected districts had a total of 29 community clusters, 9 from both Chiengi and Samfya, 6 from Luwingu, and 5 from Mungwi. Using the WHO LQAS guide, a list of all the villages in each community cluster was retrieved from the 2010 population census, and the sampling proportionate to size technique was followed to randomly select 19 households from each community cluster (23). A sampling frame was used to select households from which the individual samples were taken. The main criterion for inclusion of households was the presence of mothers with children aged 0-5 months and mothers that lived in the study site during pregnancy and delivered their baby within the same study area. In instances where two or more respondents were found in one household, and met the criteria, random sampling was done to select one respondent.

\section{Data Collection}

A pretested structured questionnaire, developed in a local language, was used in face-to-face interviews to collect data from eligible mothers of infants aged $0-5$ months. Trained research assistants conducted the interviews, asking questions on utilization of antenatal, delivery, and PNC services, which were provided at no cost in all government health facilities. Collected data included use of focused ANC during pregnancy, SBA at deliveries conducted at home or in a health facility by trained health personnel, and PNC within $48 \mathrm{~h}$ after delivery by an appropriate provider. ANC, SBA, and PNC were handled as outcome variables in this study.

The individual explanatory variables included were mother's age, attendance of school, level of education, literacy level, marital status, HIV test, HIV test results, and intermittent preventive treatment (IPTp). Like many other countries, Zambia adopted a provider-initiated HIV testing and counseling model. On first contact (preferably during first trimester) at ANC clinic, pregnant women are informed about HIV testing during group pretest counseling. Unless a woman "opts out," providers then perform a rapid HIV test that produces results within $1 \mathrm{~h}$. This service is offered as part of the standard package of ANC (24). In addition, as a preventive measure, it is recommended that pregnant women take three doses of IPTP during pregnancy; with the first dose taken after the first trimester and at least 1 month apart. The choice of explanatory variables is based on previous studies that identified these variables as some of the factors that influence the outcome variable. Therefore, we sought to test the influence of these variables in the context of the study.

Using statistics from the 2010 population census and housing survey, we extracted characteristics of the place of residence and the total population in each community cluster. Place of residence was categorized as central rural or remote rural. For this study, a central rural area is defined as a central administrative area of the district and a remote geographic area as an area further away from the central administrative area of the district. The other variable used at community level was the ratio of primary health centers (PHC) to population, categorized as less than 10,000 or above as per standards of the Ministry of Health in Zambia (25).

\section{Data Analysis and Modeling}

We calculated weighted proportions, to adjust for disproportionate sampling of mothers' use of the three indicators of maternal health services for each category in the explanatory variables. Univariate analysis was conducted for ANC, SBA, and PNC, taking the weighted odds ratio as the measure of association with the corresponding $95 \%$ confidence intervals (95\% CI). Since our data had a hierarchical structure, where 551 individual women were located within 29 clustered communities, multilevel modeling was applied in the analysis in order to account for the multistage cluster effects of the LQAS method $(12,26,27)$. The two-level model was fitted to assess the influence of measured individual and community cluster factors for each of the three indicators of maternal health services. We estimated the community-level random effects using the xtmelogit command in Stata version 13 (Stata Corp. Inc., TX, USA). In the first empty model, no independent variables were included in order to show the total variance in the use of the three maternal health services between the community clusters. In the second full model, fixed effects at individual level were included together with the community cluster-level random effects. The results of fixed effects are presented as odds ratios (ORs) with $P$-values and 95\% CIs, and random effects as variance partition coefficients (VPC) (12). The VPC was calculated as:

$$
\mathrm{VPC}_{C}=\frac{\sigma_{c}^{2}}{\sigma_{c}^{2}+3.29}
$$

where $\sigma_{c}^{2}$ represents community cluster-level variance.

\section{Ethical Clearance}

Ethical approval was obtained from research ethics committees at the Tropical Disease Research Centre (TDRC; Ref No: TRC/ C4/07/2015) in Zambia and the University of KwaZulu-Natal (Ref No: BE363/15) in South Africa. Formal permission was also obtained from the Ministry of Community Development, Mother and Child, and from the traditional leaders through the District Medical Officers of the respective selected districts. In addition, informed consent was obtained from all participants.

\section{RESULTS}

\section{Characteristics of Participants}

A total of 551 women were interviewed. As shown in Table 1, the median age for the participants was 26 years, 
TABLE 1 | Characteristics of participants in relation to utilization of maternal health-care services among the poorest populations of Zambia.

\begin{tabular}{|c|c|c|}
\hline Variables & Weighted\% (N) & $95 \% \mathrm{Cl}$ \\
\hline \multicolumn{3}{|l|}{ Age } \\
\hline $15-24$ & $41(218)$ & $(36-46)$ \\
\hline $25-40$ & $53(287)$ & $(48-58)$ \\
\hline $41-54$ & $5(27)$ & $(2-9)$ \\
\hline \multicolumn{3}{|l|}{ Marital status } \\
\hline Not married & $35(211)$ & $(32-38)$ \\
\hline Married & $65(340)$ & $(62-68)$ \\
\hline \multicolumn{3}{|c|}{ Ever attended school } \\
\hline No & $19(110)$ & $(16-23)$ \\
\hline Yes & $81(438)$ & $(77-84)$ \\
\hline \multicolumn{3}{|l|}{ Literacy } \\
\hline Cannot read at all & $63(252)$ & $(58-68)$ \\
\hline Only parts & $10(52)$ & $(7-13)$ \\
\hline Whole sentence & $27(146)$ & $(23-32)$ \\
\hline \multicolumn{3}{|c|}{ At least one antenatal care } \\
\hline \multicolumn{3}{|c|}{ (ANC) visit by skilled attendant } \\
\hline No & $31(195)$ & $(27-35)$ \\
\hline Yes & $69(356)$ & $(65-73)$ \\
\hline \multicolumn{3}{|c|}{ At least four ANC visits } \\
\hline No & $71(386)$ & $(66-75)$ \\
\hline Yes & $29(165)$ & $(25-34)$ \\
\hline \multicolumn{3}{|c|}{ Skilled birth attendant } \\
\hline No & $60(342)$ & $(56-66)$ \\
\hline Yes & 39 (209) & $(34-44)$ \\
\hline \multicolumn{3}{|c|}{$\begin{array}{l}\text { Four ANC visits with at least one } \\
\text { skilled attendance }\end{array}$} \\
\hline No & $71(389)$ & $(67-76)$ \\
\hline Yes & $29(162)$ & $(24-33)$ \\
\hline \multicolumn{3}{|l|}{ Did an HIV test } \\
\hline No & $23(124)$ & $(19-27)$ \\
\hline Yes & $78(427)$ & $(73-81)$ \\
\hline \multicolumn{3}{|c|}{ Received HIV test results } \\
\hline No & $27(154)$ & $(23-32)$ \\
\hline Yes & $73(397)$ & $(24-32)$ \\
\hline \multicolumn{3}{|c|}{ Received IPT2 during pregnancy } \\
\hline No & $35(191)$ & $(31-40)$ \\
\hline Yes & $65(360)$ & $(60-69)$ \\
\hline \multicolumn{3}{|c|}{ Delivered from health facility } \\
\hline No & $43(234)$ & $(39-48)$ \\
\hline Yes & $57(317)$ & $(52-61)$ \\
\hline \multicolumn{3}{|c|}{ Exclusively breastfed } \\
\hline No & $43(259)$ & $(39-48)$ \\
\hline Yes & $56(292)$ & $(52-61)$ \\
\hline \multicolumn{3}{|c|}{ Postnatal care (maternal) within } \\
\hline \multicolumn{3}{|c|}{$48 \mathrm{~h}$ by an appropriate provider } \\
\hline No & $71(397)$ & $(65-75)$ \\
\hline Yes & $29(154)$ & $(25,34)$ \\
\hline
\end{tabular}

Cl, 95\% confidence interval.

Design was a cross-sectional survey using lot quality assurance sampling method.

with a range of $15-54$ years. One in five mothers (20\%) had never been to school, and mothers, who could not read at all, were as high as $63 \%$ among the respondents. Among the mothers, $78 \%$ reported to have had an HIV test done during their last pregnancy, but $27 \%$ did not receive their HIV test results.

\section{Utilization of Maternal Health Services}

As shown in Table 1, the proportion of women who had received $\mathrm{ANC}$ at least once for their most recent birth in the past 5 months preceding the survey was 69\% (95\% CI: 65-73). However, the proportion of mothers that had attended the WHO-recommended focused ANC was much lower, at only $29 \%$ (95\% CI: 25-34). The proportion of women who had delivered in a health facility was $57 \%$ (95\% CI: $52-61)$, and only $39 \%(95 \%$ CI: 34-44) reported receiving assistance at childbirth by skilled personnel. Our results also show that only $29 \%$ (95\% CI: 25-34) of women had PNC within $48 \mathrm{~h}$.

\section{Predictors of Utilization}

\section{Single Level Analysis}

Education was an important predictor for focused ANC and SBA at delivery, as shown in Table 2. Women who have been to school were 2.17 times and 2.46 times more likely to attend focused ANC and SBA at delivery, respectively.

As shown in Table 2, women who could read the whole sentence were $1.71,2.21$, and 2.12 times $(P<0.05)$ more likely to use focused ANC, SBA, and PNC within $48 \mathrm{~h}$, respectively, than women who could not read.

Furthermore, women who received ANC at least once from a skilled personnel $(P<0.01)$ and at least four times $(P<0.01)$ were more likely to have received assisted skilled delivery. Mothers who took an HIV test and those who received the HIV test results $(P<0.01)$ were more likely to be users of SBA and PNC. Most of the predictor variables for SBA were also significantly associated $(P<0.01)$ with use of PNC within $48 \mathrm{~h}$ of delivery by a skilled provider (see Table 2 ). In addition, women who had SBA at the health facility were more likely $(P<0.01)$ to use PNC within $48 \mathrm{~h}$ after delivery. Under the community-level predictors, our analysis shows that women who live in central rural areas were more likely to use SBA and PNC within $48 \mathrm{~h}$ after birth than those living in remote rural areas $(P<0.01)$. For instance, women living in central rural areas were 3.11 times more likely to receive SBA than women living in remote rural communities. However, our analysis did not find substantial association between the ratios of PHC to community population with the use of all the three indicators of maternal health care services.

\section{Multilevel Analysis}

For the initial multilevel analysis, we started with an empty random two-level intercept model to test the null hypothesis that there is no variation in the effects of maternal health service utilization between community clusters, the results of which show considerable variation across the communities, particularly for SBA. Based on the VPC values in the empty model shown in Table 3, 9\% of the total variance in the use of focused ANC, $27 \%$ variance in the use of SBA, and $22 \%$ variance in the use of PNC within $48 \mathrm{~h}$ were attributable to the unobserved differences across community clusters. Furthermore, the results show significantly reduced odds for utilizing focused ANC, SBA, and PNC within 48 h by $60 \%$ (OR 0.40; $95 \%$ CI: $0.30-0.53$ ), 47\% (OR 0.53; 95\% CI: 0.34-0.84), and 67\% (OR 
TABLE 2 | Univariate analysis [odds ratio (OR) with $95 \%$ confidence interval $(95 \% \mathrm{CI})$ ] of the predictors of the indicators of the use of maternal healthcare services among the poor rural populations of Zambia.

\begin{tabular}{|c|c|c|c|c|c|c|c|c|c|}
\hline \multirow[t]{2}{*}{ Factors } & \multicolumn{3}{|c|}{$\begin{array}{c}\text { Received antenatal care (ANC) } \\
\text { at least four times (FANC) }\end{array}$} & \multicolumn{3}{|c|}{ Skilled attendance at delivery } & \multicolumn{3}{|c|}{$\begin{array}{l}\text { Received postnatal care within } \\
\qquad 48 \mathrm{~h} \text { after delivery }\end{array}$} \\
\hline & $n / N$ & OR $(95 \% \mathrm{Cl})$ & $P$-value & $n / N$ & OR $(95 \% \mathrm{Cl})$ & $P$-value & $n / N$ & OR $(95 \% \mathrm{Cl})$ & $P$-value \\
\hline \multicolumn{10}{|l|}{ Age } \\
\hline $15-24$ & $57 / 218$ & 1 & & $91 / 218$ & 1 & & $62 / 218$ & 1 & \\
\hline $24-40$ & $93 / 287$ & $1.40(0.88-2.23)$ & 0.154 & $102 / 287$ & $0.71(0.46-1.11)$ & 0.138 & $80 / 287$ & $0.84(0.52-1.35)$ & 0.468 \\
\hline $41-54$ & $11 / 27$ & $2.13(0.76-6.05)$ & 0.152 & $11 / 27$ & $1.26(0.46-3.45)$ & 0.649 & 9/27 & $1.50(0.52-4.35)$ & 0.451 \\
\hline \multicolumn{10}{|l|}{ Marital status } \\
\hline Married & $56 / 211$ & 1 & & $84 / 211$ & 1 & & $68 / 211$ & 1 & \\
\hline Not married & $109 / 340$ & $1.48(0.92-2.4)$ & 0.101 & $125 / 340$ & $1.45(0.94-2.21)$ & 0.088 & $86 / 340$ & $1.22(0.77-1.91)$ & 0.393 \\
\hline \multicolumn{10}{|c|}{ Ever been to school } \\
\hline No & $21 / 110$ & 1 & & 28/110 & 1 & & $25 / 110$ & 1 & \\
\hline Yes & $143 / 438$ & $2.17(1.23-3.83)$ & 0.008 & $181 / 438$ & $2.46(1.42-4.26)$ & 0.001 & $129 / 438$ & $1.38(0.79-2.44)$ & 0.260 \\
\hline \multicolumn{10}{|l|}{ Literacy } \\
\hline Cannot read at all & $92 / 351$ & 1 & & $111 / 351$ & 1 & & $76 / 351$ & 1 & \\
\hline Only parts & $17 / 53$ & 1.85 (0.90-3.79) & 0.093 & 28/53 & $2.90(1.45-5.77)$ & 0.003 & $20 / 53$ & $2.07(1.02-4.22)$ & 0.045 \\
\hline Whole sentence & $56 / 147$ & $1.71(1.05-2.80)$ & 0.032 & $70 / 147$ & $2.21(1.38-3.53)$ & 0.001 & $58 / 147$ & $2.12(1.27-3.53)$ & 0.004 \\
\hline \multicolumn{10}{|l|}{ Took the HIV test } \\
\hline No & $16 / 124$ & 1 & & $13 / 124$ & & & $6 / 124$ & & \\
\hline Yes & $149 / 427$ & $3.53(1.91-6.55)$ & 0.000 & $196 / 427$ & $5.79(2.87-11.67)$ & 0.000 & $148 / 427$ & $6.88(2.58-18.38)$ & 0.000 \\
\hline \multicolumn{10}{|c|}{ Received HIV test results } \\
\hline No & 30/154 & 1 & & $21 / 154$ & 1 & & $14 / 154$ & 1 & \\
\hline Yes & $135 / 397$ & $2.17(1.3-3.58)$ & 0.003 & $188 / 397$ & 4.97 (2.79-8.84) & 0.000 & $140 / 397$ & $4.48(2.26-8.86)$ & 0.000 \\
\hline \multicolumn{10}{|c|}{ Received IPT2 during pregnancy } \\
\hline No & 29/191 & 1 & & $49 / 191$ & & & $42 / 191$ & & \\
\hline Yes & $136 / 360$ & $3.59(2.14-6.00)$ & 0.00 & $160 / 360$ & $1.75(1.11-2.75)$ & 0.015 & $112 / 360$ & $1.22(0.74-1.99)$ & 0.421 \\
\hline \multicolumn{10}{|c|}{ ANC once with a skilled attendance } \\
\hline No & $\star \star$ & $\star \star$ & $\star \star$ & $172(342)$ & 1 & & $218(397)$ & 1 & \\
\hline Yes & & & & $184(209)$ & $5.93(3.50-10.05)$ & 0.000 & $137(154)$ & $5.63(3.09-10.27)$ & 0.000 \\
\hline \multicolumn{10}{|c|}{ ANC at least four time } \\
\hline No & 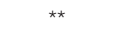 & $\star \star$ & $\star \star$ & $122 / 386$ & 1 & & $89 / 386$ & 1 & \\
\hline Yes & & & & $87 / 165$ & $2.41(1.66-3.50)$ & 0.000 & $65 / 165$ & $1.50(0.95-2.38)$ & 0.081 \\
\hline \multicolumn{10}{|c|}{ Skilled birth attendants } \\
\hline No & ** & $\star \star$ & $\star \star$ & ** & ** & $\star \star$ & 20/342 & 1 & 0.000 \\
\hline Yes & & & & & & & $134 / 209$ & $40.19(21.45-75.31)$ & 0.000 \\
\hline \multicolumn{10}{|c|}{ Delivery at health facility } \\
\hline No & ** & $\star \star *$ & $\star \star$ & 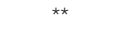 & ** & ** & $3 / 234$ & 1 & \\
\hline Yes & & & & & & & $151 / 317$ & $96.81(27.98-134.96)$ & 0.000 \\
\hline \multicolumn{10}{|c|}{ Community-level factors } \\
\hline \multicolumn{10}{|c|}{ Type of residence } \\
\hline Remote rural & $137 / 455$ & 1 & & $153 / 455$ & 1 & & $115 / 455$ & 1 & \\
\hline Central rural & 28/96 & $0.93(0.55-1.60)$ & 0.80 & $56 / 96$ & $3.11(1.89-5.10)$ & 0.000 & 39/96 & $2.02(1.27-3.20)$ & 0.004 \\
\hline \multicolumn{10}{|c|}{ Ratio of health facilities to population in the SA } \\
\hline Up to 10,000 & $92 / 285$ & 1 & & 106 & 1 & & $74 / 285$ & 1 & \\
\hline$>10,000$ & $73 / 266$ & $0.84(0.55-1.29)$ & 0.426 & 103 & $1.15(0.77-1.71)$ & 0.487 & $80 / 266$ & 1.50 (0.96-2.33) & 0.075 \\
\hline
\end{tabular}

Statistical significance at $P<0.05 ; \mathrm{Cl}$, confidence interval.

${ }^{*}$ Variables that could not be regressed against the other variable.

0.33; 95\% CI: 0.22-0.49), respectively, across the communities. See Table 3.

After the empty two-level intercept modeling with only random effects, a full multilevel model was run to assess predictors of the three indicators of maternal health-care services. The model included fixed effects at individual and community levels, and the findings are presented in Table 4.

\section{Antenatal Care}

As shown in Table 4, compared to younger women, older women were four times (OR 4.04; 95\% CI: 1.52-10.78) more likely to attend $\mathrm{ANC}$ at least four times.

Furthermore, the multilevel analysis indicates a positive association $(P<0.01)$ between focused ANC and taking an HIV test, receiving HIV test results, and receiving IPTp2 for 
malaria at least twice. Although statistically insignificant, the odds of reporting use of ANC by women who had ever attended school was 3.47 times higher (OR 3.47; 95\% CI: 0.48-24.98).

TABLE 3 | Parameter coefficients for the multilevel model for various indicators of the use of maternal health services-empty model without covariates.

Antenatal care $\begin{gathered}\text { Skilled attendance } \\ \text { at delivery }\end{gathered}$

Level 2 variance - random effects

Community (SA) $\quad 0.40(0.30-0.53) \quad 0.53(0.34-0.84) \quad 0.33(0.22-0.49)$

odds ratio $(\mathrm{Cl})$

$\begin{array}{llll}\text { Community (SA) } & 9 & 27 & 22 \\ \text { VPC (\%) } & & \end{array}$

Cl, confidence interval; VPC, variance partition coefficients.
At community level, the type of residence (that is women in centralized rural areas) shows a negative trend toward utilization of focused ANC, though results were statistically non-significant. The ratio of $\mathrm{PHCs}$ to the population in the community cluster above 10,000 people did not predict use of ANC. Our results show a marginal 2\% decrease, from 9 to $7 \%$, of the VPC for use of ANC, indicating a very minimal decrease in the clustering of ANC utilization even after controlling for individual- and community-level variables.

\section{Skilled Birth Attendance}

The significant individual-level variables that predict SBA included; literacy, ANC attendance, and having received HIV test results, as shown in Table 4. Women who could read some parts of a sentence were positively associated with SBA (OR 2.73; 95\% CI: 1.23-6.18). Having received at least one ANC by a skilled provider in the recent pregnancies had a positive influence (OR

TABLE 4 | Results of the multilevel analysis of the factors related to the use of maternal health services among the poor rural populations of Zambia.

Variables

Adjusted odds ratios $(\mathrm{Cl})$

\begin{tabular}{cccc}
\hline Characteristics & $\begin{array}{c}\text { Antenatal care at least } \\
\text { four times (FANC) }\end{array}$ & $\begin{array}{c}\text { Skilled attendance } \\
\text { at delivery }\end{array}$ & Postnatal care
\end{tabular}

\section{Fixed effects}

Individual variables

Age

Marital status

Ever attended school

Literacy

Took HIV test

Received HIV test results

Received intermittent preventive treatment 2

ANC1 with skilled personnel

ÀNC4

Delivery at a health facility

Skilled birth attendance

\begin{tabular}{|c|c|}
\hline $15-24$ & 1 \\
\hline $24-40$ & $1.78(1.13-2.81)^{*}$ \\
\hline $41-54$ & $4.04(1.52-10.78)^{\star}$ \\
\hline Not married & 1 \\
\hline Married & $1.43(0.84-2.44)$ \\
\hline No & 1 \\
\hline Yes & $3.47(0.48-24.98)$ \\
\hline Cannot read at all & 1 \\
\hline Only parts & $1.12(0.53-3.86)$ \\
\hline Whole sentence & $1.21(0.65-2.38)$ \\
\hline No & 1 \\
\hline Yes & $5.73(2.09-15.77)^{\star \star}$ \\
\hline No & 1 \\
\hline Yes & $0.38(0.16-0.91)^{*}$ \\
\hline No & 1 \\
\hline Yes & $3.62(2.10-6.21)^{\star \star \star}$ \\
\hline No & \\
\hline Yes & \\
\hline No & \\
\hline Yes & \\
\hline No & \\
\hline Yes & \\
\hline No & \\
\hline Yes & \\
\hline
\end{tabular}

\section{Community (SA) level variables}

Type of residence

Remote rural

Central rural

Ratio of health facilities to population in the SA

Up to 10,000

$$
>10,000
$$

Random effects

Community (SA) random variance (SE)

Community (SA) VPC (\%)

SA, supervisory area; VPC, variance partition coefficients.

${ }^{*} P<0.05$.

${ }^{* *} P<0.01$.

${ }^{* * *} P<0.001$.

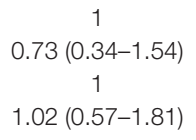

$0.245(0.16)$

7
1

$0.81(0.50-1.31)$

$1.69(0.58-4.94)$

1

0.97 (0.54-1.77)

1

$2.28(0.27-19.44)$

1

$2.73(1.23-6.18)^{\star \star}$

$1.29(0.68-2.44)$

1

$2.21(1.70-4.93)^{\star}$

1

$1.98(0.75-5.27)$

1

$1.56(0.93-2.64)$

1

$4.48(2.38-8.43)^{\star \star \star}$

1

$1.05(0.62-1.77)$

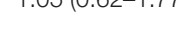

$$
\begin{aligned}
& 1.42(0.77-2.61) \\
& 2.09(0.53-8.25) \\
& 1 \\
& 0.69(0.35-1.39) \\
& 1 \\
& 0.13(0.02-1.84) \\
& 1 \\
& 1.34(0.52-3.45) \\
& 1.63(0.72-3.68) \\
& 1 \\
& 6.18(1.20-28.16)^{*} \\
& 1 \\
& 0.65(0.19-2.20) \\
& 1 \\
& 0.69 \text { (0.34-1.395) } \\
& 1 \\
& 2.42(1.40-5.62)^{\star} \\
& 1 \\
& 0.87(0.44-1.72) \\
& 1 \\
& 17.42(4.67-54.95)^{\star \star \star} \\
& 9.48(4.42-20.34)^{\star \star \star} \\
& 1 \\
& 0.88(0.33-2.36) \\
& 1.50(0.69-3.25)
\end{aligned}
$$$$
0.93(0.45-1.93)
$$ 
4.48; 95\% CI, 2.38-8.43) on SBA. Women who had received HIV test results had a 3.80 likelihood of SBA. As shown in Table 4, compared to women residing in remote rural areas, women in central rural areas were 2.72 times (OR 2.57; 95\% CI: 1.37-6.82) more likely to have a delivery by a skilled attendant. The VPC in the use of skilled delivery reduced from $27 \%$ in the empty model to $14 \%$, indicating continued clustering of utilization of SBA even after controlling for individual- and community-level factors.

\section{Postnatal Care}

Use of at least one ANC provided by skilled personnel, having taken an HIV test during pregnancy, SBA, and delivering at a health facility were the only predictor variables that were significantly associated with utilization of PNC by women within $48 \mathrm{~h}$ of delivery. As shown in Table 4, the odds of using PNC within $48 \mathrm{~h}$ of delivery by an appropriate provider was 2.42 times (OR 2.42; 95\% CI: 1.04-5.62) among women who received at least one ANC by a skilled personnel and 9.48 times (OR 9.48; 95\% CI: 4.42-20.33) among women that had skilled assistance at delivery.

Likewise, a positive association was found between the use of PNC and delivering at a health facility. Our analysis did not find a significant influence in the use of PNC by the type of residence or the ratio of PHCs to population in the community cluster.

\section{DISCUSSION}

In this study, we sought to investigate utilization patterns and determinants of the three indicators of continuity of care for maternal health-care services, ANC, SBA, and PNC, among the most remote, rural, and poor communities of Zambia, and five key lessons were observed. First, the remote rural mothers living in poor communities had much lower utilization rates of maternal health-care services compared to the national average for rural Zambia, they were therefore worse off given their marginalized location. Second, both focused ANC and SBA were predicted by an HIV test when HIV test results are also provided to mothers, indicating the importance of HIV testing as a driver of service utilization. Third, a single ANC provided by a skilled health worker was a predictor of both SBA and PNC within $48 \mathrm{~h}$, a potential bridge for the lower rates of focused ANC in these communities. Fourth, women in remote rural areas were found to be at a disadvantage, and less likely to utilize SBA when compared to women in centralized rural areas. Finally, PNC within $48 \mathrm{~h}$ was predicted by both SBA and delivery at a health facility, reiterating the importance of institutional delivery. However, less than $40 \%$ of women in this study had a SBA, suggesting probable missed opportunities in PNC for the $60 \%$ of women who did not have a SBA.

Overall, utilization of the three indicators of maternal health services in these rural and remote populations was very low, with only a third of women receiving focused ANC and PNC within $48 \mathrm{~h}$ and less than half receiving SBA. These coverage levels are much lower than the national estimates for rural areas in Zambia (11) and other sub-Saharan African countries (2, $10,12,14,28)$. For instance, compared to the ZDHS national estimates of $55.2 \%$ of women in rural areas attend at least four
ANC visits $29 \%$ of women in remote areas attended ANC at least four times.

Meanwhile, $39 \%$ of women in these remote communities had a skilled attendant at delivery compared to the ZDHS national estimates of $52 \%$ of women delivered by a skilled provider in rural areas.

At individual level, attendance of ANC at least four times was found to be positively influenced by the age of the woman, having taken an HIV test, having received results for an HIV test, and having received prevention for malaria. It was not surprising that older women were more likely to use ANC services given that previous studies have reported a positive association between the age of the woman and use of ANC in similar contexts $(12,28-30)$. Older women are also more knowledgeable about health-care services (30), have greater decision-making power than younger women, and are thus benefiting from using such services, hence the higher likelihood of utilization (31). In addition, older age as a predictor of utilization of ANC services could also be related to greater likelihood of having a previous birth and interaction with services. However, some studies show a lack of association between maternal age and health service utilization (32).

Findings regarding a positive association between the number of ANC visits attended and having tested for HIV are consistent with other studies in the region $(33,34)$. Routine HIV testing during ANC visits seems to provide a condition for attending $\mathrm{ANC}$, and therefore, women who attend ANC are more likely to be tested (35).

Consistent with prior research in rural Kenya (36) and elsewhere $(10,30,37,38)$, this study found literacy status of women as an influential predictor for the use of SBA. Women that are able to read are more likely to have better access to information on health matters. It is also likely that literate women have more confidence, are capable in making decisions about their health $(28,36)$, have better socioeconomic status, and are better placed to overcome cultural barriers to maternal health-care use $(16,39)$.

Some researchers, however, question the independent association of literacy on MNH services utilization. They argue that other factors such as husband's educational level and socioeconomic environment interact to dilute the association (40, 41).

Most notably, our study found that receiving at least one ANC from a skilled provider had a noteworthy effect on the use of both SBA and PNC within $48 \mathrm{~h}$ of child birth, a finding supported by only one other study in Ethiopia (13). The positive contribution of at least one ANC visit by a skilled provider on use of SBA and PNC, observed in rural and remote areas of Zambia where distance is a challenge to accessing services (42), may have implications to policy and practice. These findings are contrary to what most studies have reported that women who attend less than the recommended four ANC visits are less likely to receive SBA $(10,31)$.

As observed in previous studies $(43,44)$, our study confirms the significant association of previous use of maternal health services on subsequent services. The predictor SBA in this study demonstrates that women tend to use PNC services if they were 
attended by skilled personnel at delivery. One of the expected effects of giving birth with skilled attendants is that it reinforces the use of PNC services. Worku et al. (13) argue that women who tend to use maternal health-care services build confidence in skilled providers and their care. Moreover, based on the effect of use of ANC on SBA and PNC found in this study and elsewhere (44), it seems right to consider ANC visits as a feasible entry point for subsequent utilization of the indicators of maternal health services.

Consistent with other studies $(12,13)$, finding that women who live in central rural areas were more likely to attend an assisted delivery, is an indicator of inequity for those mothers located on the margins of society, and socially excluded from maternal health care services. Some studies have also shown that within the poor rural areas, the patterns of maternal health care service utilization vary widely $(3,12,45)$.

This could be a reflection of varying contextual and geo-social differences that span across these communities even if they may all be grouped as poor and vulnerable populations. Therefore, context matters, and an understanding of the context of the variations in the use of maternal health services based on place of residence is required to design interventions that address inequalities, as argued by Say and Raine (46).

\section{Limitations}

This study may have suffered from some limitations that could have affected our findings. Selection bias could have occurred as a result of the cross-sectional design used for this study, and the use of LQAS, which has been designed to measure group variables rather than individual variables. Inclusion of only women with surviving infants could have also led to selection bias. Also, measurement biases could have occurred due to limited variables, missing others that could have explained other associations, such as economic status and distance to the health facility. The data analyzed was self-reported and therefore subject to social desirability and recall bias, though women were interviewed within 5 months of childbirth. However, although we think that these biases were present, we do not think they are important in explaining the findings. First, pregnancy and childbirth are revered in these rural communities, such that women would not easily forget their experiences. Furthermore, we used multilevel modeling to control for the effects of between and within group variability, and estimated the effects of group (cluster) level characteristics on outcomes. Notably, using LQAS-based data to measure individual effects in this study, considering the original aim of such methodology, is a novel and demand driven approach. The use of LQAS as a rapid methodology for monitoring programs is a feasible and quick measure for obtaining data on a large scale, and as such, could be used to rapidly inform interventions and policies without waiting for the slow expensive demographic and health surveys currently being employed. For these reasons, we think that these results can be extrapolated to similar communities in Zambia, not withstanding differential contextual contrasts that may exist. In view of such variations, generalizing these results in other low income settings must be done with caution.

\section{CONCLUSION}

In this study, we have found that utilization of key indicators of maternal health services among the remote and poorest rural populations of Zambia is very low and much lower than the national estimates. Only a third of mothers achieved the WHOrecommended focused ANC, with a third of mothers not having been to ANC at all. Women were more likely to attend focused ANC when they were offered an HIV test and given results for HIV tests, indicating the importance of HIV testing as a driver of service utilization. Importantly, we have found that receiving ANC once from a skilled attendant is a significant predictor of both SBA and PNC within $48 \mathrm{~h}$, by women in these remote and poorest populations of Zambia, a potential bridge for the lower rates of focused ANC in these communities. Based on these results, contact with skilled health-care providers seems very important for use of services in these rural remote communities. Our finding of remote rural communities being at a disadvantage, and less likely to receive SBA when compared with centralized rural areas, suggests that disparities in the use of $\mathrm{MH}$ services do exist within rural populations.

Therefore, we recommend that remote and poor women, who are unable to frequently attend ANC services, may benefit from SBA and PNC by attending at least one ANC visit offered by a skilled provider. We also recommend further research to understand the perspectives of women toward focused ANC and explore the barriers to utilization of focused ANC in the remote and poorest rural populations.

\section{AUTHOR CONTRIBUTIONS}

CJ, CM, and MM conceptualized the study. CJ, CM, NL, and SM participated in data collection and cleaning. CJ, CM, NL, and SM participated in designing the study. CJ, MM, and CM participated in data analysis. CJ prepared the first draft of the manuscript. MM and CM provided scientific advices on data analysis and throughout the preparation of the manuscript. All the authors worked on revising various drafts of the manuscript. All the authors read and approved the final draft.

\section{ACKNOWLEDGMENTS}

We are very grateful to UNICEF Zambia and Ministry of health officials for their participation in data collection. We thank Mainga Banda, Camielle Noordam, Ngashi Ngongo, and Nicholas Oliphant from UNICEF particularly for providing technical support to the team. We are also very thankful to Ben Sartorius and Patrick Musonda for the analytical support. The authors are also grateful to all the subjects who participated in this study for their commitment in responding to the interviews. We also acknowledge the support provided by the research Support Centre at UNZA-SoM through the Southern African Consortium for Research Excellence (SACORE), which is part of the African Institutions Initiative grant of the Welcome Trust (company no. 2711000), a charity (no. 210183) registered in England for analytical support and a $\mathrm{PhD}$ small grant, as well as MEPI for the support for scientific writing training. 


\section{REFERENCES}

1. Adogu PO, Egenti BN, Ubajaka C, Onwasigwe C, Nnebue CC. Utilization of maternal health services in urban and rural communities of Anambra State, Nigeria. Nig J Med (2014) 23(1):61-9.

2. Tracy L, Sagbakken M. Exploration of perceptions and decision-making processes related to childbirth in rural Sierra Leone. BMC Pregnancy Childbirth (2015) 15(1):1. doi:10.1186/s12884-015-0500-9

3. Kiwanuka S, Ekirapa E, Peterson S, Okui O, Rahman MH, Peters D, et al. Access to and utilisation of health services for the poor in Uganda: a systematic review of available evidence. Trans $R$ Soc Trop Med Hyg (2008) 102(11):1067-74. doi:10.1016/j.trstmh.2008.04.023

4. Filippi V, Ronsmans C, Campbell OM, Graham WJ, Mills A, Borghi J, et al. Maternal health in poor countries: the broader context and a call for action. Lancet (2006) 368(9546):1535-41. doi:10.1016/S0140-6736(06) 69384-7

5. Lincetto O, Mothebesoane-Anoh S, Gomez P, Munjanja SP. Antenatal care. In: Joy L, Kate K, editors. Opportunities for Africa's Newborns: Practical Data, Policy and Programmatic Support for Newborn Care in Africa. Cape Town: PMNCH (2006). Available from: http://www.who.int/pmnch/media/ publications/africanewborns/en/

6. Islam M, Yoshida S. MDG 5: how close are we to success? BJOG (2009) 116(1):2-5. doi:10.1111/j.1471-0528.2009.02335.x

7. Winch PJ, Alam MA, Akther A, Afroz D, Ali NA, Ellis AA, et al. Local understandings of vulnerability and protection during the neonatal period in Sylhet District, Bangladesh: a qualitative study. Lancet (2005) 366(9484):478-85. doi:10.1016/S0140-6736(05)66836-5

8. Thomsen S, Hoa DTP, Målquist M, Sanneving L, Saxena D, Tana S, et al. Promoting equity to achieve maternal and child health. Reprod Health Matters (2011) 19(38):176-82. doi:10.1016/S0968-8080(11)38586-2

9. Warren C. Care seeking for maternal health: challenges remain for poor women. Ethiopian J Health Dev (2010) 24(1). doi:10.4314/ejhd. v24i1.62950

10. Babalola S, Fatusi A. Determinants of use of maternal health services in Nigeria-looking beyond individual and household factors. BMC Pregnancy Childbirth (2009) 9(1):43. doi:10.1186/1471-2393-9-43

11. Zambia Central Statistical Office, the DHS Program, ICF International, Rockville, Maryland, USA. Zambia Demographic and Health Survey 2013-14. Rockville, MD: Lusaka Zambia, the DHS Program, ICF International (2014). Available from: http://dhsprogram.com/pubs/pdf/FR304/FR304.pdf

12. Jat TR, Ng N, San Sebastian M. Factors affecting the use of maternal health services in Madhya Pradesh state of India: a multilevel analysis. Int J Equity Health (2011) 10:59. doi:10.1186/1475-9276-10-59

13. Worku AG, Yalew AW, Afework MF. Factors affecting utilization of skilled maternal care in Northwest Ethiopia: a multilevel analysis. BMC Int Health Hum Rights (2013) 13(1):20. doi:10.1186/1472-698X-13-20

14. Chama-Chiliba CM, Koch SF. Utilization of focused antenatal care in Zambia: examining individual-and community-level factors using a multilevel analysis. Health Policy Plan (2015) 30(1):78-87. doi:10.1093/heapol/ czt099

15. Mrisho M, Obrist B, Schellenberg JA, Haws RA, Mushi AK, Mshinda $\mathrm{H}$, et al. The use of antenatal and postnatal care: perspectives and experiences of women and health care providers in rural southern Tanzania. BMC Pregnancy Childbirth (2009) 9:10. doi:10.1186/1471-23939-10

16. Mrisho M, Schellenberg JA, Mushi AK, Obrist B, Mshinda H, Tanner M, et al. Factors affecting home delivery in rural Tanzania. Trop Med Int Health (2007) 12(7):862-72. doi:10.1111/j.1365-3156.2007.01855.x

17. Simkhada B, Teijlingen ER, Porter M, Simkhada P. Factors affecting the utilization of antenatal care in developing countries: systematic review of the literature. J Adv Nurs (2008) 61(3):244-60. doi:10.1111/j.1365-2648. 2007.04532.x

18. Van Eijk AM, Bles HM, Odhiambo F, Ayisi JG, Blokland IE, Rosen DH, et al. Use of antenatal services and delivery care among women in rural western Kenya: a community based survey. Reprod Health (2006) 3(1):2. doi:10.1111/j.1365-2648.2007.04532.x

19. Chapoto A, Banda DJ, Haggblade S, Hamukwala P. Factors Affecting Poverty Dynamics in Rural Zambia. Food Security Research Project, Working Paper
No. 55. Lusaka: Michigan State University, Department of Agricultural, Food, and Resource Economics (2011).

20. Central Statistical Office Zambia. Zambia 2010 Census of Population and Housing. Lusaka: CSO (2010).

21. Dhakal S, Chapman GN, Simkhada PP, Van Teijlingen ER, Stephens J, Raja AE. Utilisation of postnatal care among rural women in Nepal. BMC Pregnancy Childbirth (2007) 7(1):19. doi:10.1186/1471-2393-7-19

22. Magoma M, Requejo J, Campbell OM, Cousens S, Filippi V. High ANC coverage and low skilled attendance in a rural Tanzanian district: a case for implementing a birth plan intervention. BMC Pregnancy Childbirth (2010) 10:13. doi:10.1186/1471-2393-10-13

23. Greenland K, Rondy M, Chevez A, Sadozai N, Gasasira A, Abanida E, et al. Clustered lot quality assurance sampling: a pragmatic tool for timely assessment of vaccination coverage. Trop Med Int Health (2011) 16(7):863-8. doi:10.1111/j.1365-3156.2011.02770.x

24. World Health Organization. Antiretroviral Drugs for Treating Pregnant Women and Preventing HIV Infection in Infants: Recommendations for a Public Health Approach-2010 Version. World Health Organization (2010). Available from: http://www.who.int/iris/handle/10665/75236

25. Ferrinho P, Siziya S, Goma F, Dussault G. The human resource for health situation in Zambia: deficit and maldistribution. Hum Resour Health (2011) 9(1):30. doi:10.1186/1478-4491-9-30

26. Goldstein H. Multilevel Statistical Models. 3rd ed. London: Arnold (2003).

27. DiPrete TA, Forristal JD. Multilevel models: methods and substance. Ann Rev Soc (1994) 20(1):331-57. doi:10.1146/annurev.so.20.080194.001555

28. Regassa N. Antenatal and postnatal care service utilization in southern Ethiopia: a population-based study. Afr Health Sci (2011) 11(3).

29. Tsegay Y, Gebrehiwot T, Goicolea I, Edin K, Lemma H, San Sebastian M. Determinants of antenatal and delivery care utilization in Tigray region, Ethiopia: a cross-sectional study. Int J Equity Health (2013) 12(1):1. doi:10.1186/1475-9276-12-30

30. Subba D. Maternal complications and the utilisation of maternal health care services with special reference to West Bengal, India. Open J Obstet Gynecol (2013) 03(09):694-701. doi:10.4236/ojog.2013.39128

31. Reynolds HW, Wong EL, Tucker H. Adolescents' use of maternal and child health services in developing countries. Int Family Plan Perspect (2006) 32(1):6-16. doi:10.1363/3200606

32. Magadi MA, Agwanda AO, Obare FO. A comparative analysis of the use of maternal health services between teenagers and older mothers in sub-Saharan Africa: Evidence from Demographic and Health Surveys (DHS). Soc Sci Med (2007) 64(6):1311-25. doi:10.1016/j.socscimed.2006. 11.004

33. Perez F, Zvandaziva C, Engelsmann B, Dabis F. Acceptability of routine HIV testing ("opt-out") in antenatal services in two rural districts of Zimbabwe. JAIDS (2006) 41(4):514-20. doi:10.1097/01.qai.0000191285.70331.a0

34. Gupta S, Yamada G, Mpembeni R, Frumence G, Callaghan-Koru JA, Stevenson R, et al. Factors associated with four or more antenatal care visits and its decline among pregnant women in Tanzania between 1999 and 2010. PLoS One (2014) 9(7):e101893. doi:10.1371/journal.pone.0101893

35. Williams B, Costello M, McHugh E, Le Prevost M, Phil-Ebosie A, Tilsed C, et al. Repeat antenatal HIV testing in the third trimester: a study of feasibility and maternal uptake rates. HIV Med (2014) 15(6):362-6. doi:10.1111/ hiv. 12110

36. Kawakatsu Y, Sugishita T, Oruenjo K, Wakhule S, Kibosia K, Were E, et al. Determinants of health facility utilization for childbirth in rural western Kenya: cross-sectional study. BMC Pregnancy Childbirth (2014) 14(1):265. doi:10.1186/1471-2393-14-265

37. Chakraborty N, Islam MA, Chowdhury RI, Bari W, Akhter HH. Determinants of the use of maternal health services in rural Bangladesh. Health Promot Int (2003) 18(4):327-37. doi:10.1093/heapro/dag414

38. Costello A, Osrin D, Manandhar D. Reducing maternal and neonatal mortality in the poorest communities. BMJ (2004) 329(7475):1166. doi:10.1136/ bmj.329.7475.1166

39. Addai I. Determinants of use of maternal-child health services in rural Ghana. J Biosoc Sci (2000) 32(1):1-15.

40. Gage AJ, Guirlène Calixte M. Effects of the physical accessibility of maternal health services on their use in rural Haiti. Popul Stud (2006) 60(3):271-88. doi:10.1080/00324720600895934 
41. Raghupathy S. Education and the use of maternal health care in Thailand. Soc Sci Med (1996) 43(4):459-71. doi:10.1016/0277-9536(95)00411-4

42. Gabrysch S, Cousens S, Cox J, Campbell OM. The influence of distance and level of care on delivery place in rural Zambia: a study of linked national data in a geographic information system. PLoS Med (2011) 8(1):150. doi:10.1371/ journal.pmed.1000394

43. Gage AJ. Barriers to the utilization of maternal health care in rural Mali. Soc Sci Med (2007) 65(8):1666-82. doi:10.1016/j.socscimed.2007.06.001

44. Singh PK, Kumar C, Rai RK, Singh L. Factors associated with maternal healthcare services utilization in nine high focus states in India: a multilevel analysis based on 14385 communities in 292 districts. Health Policy Plan (2014) 29(5):542-59. doi:10.1093/heapol/czt039

45. Flaskerud JH, Lesser J, Dixon E, Anderson N, Conde F, Kim S, et al. Health disparities among vulnerable populations: evolution of knowledge over five decades in Nursing Research publications. Nurs Res (2002) 51(2):74-85. doi:10.1097/00006199-200203000-00003

46. Say L, Raine R. A systematic review of inequalities in the use of maternal health care in developing countries: examining the scale of the problem and the importance of context. Bull World Health Org (2007) 85(10):812-9. doi:10.2471/BLT.06.035659

Conflict of Interest Statement: The authors declare that the research was conducted in the absence of any commercial or financial relationships that could be construed as a potential conflict of interest.

The reviewers HT and LK and handling Editor declared their shared affiliation, and the handling Editor states that the process nevertheless met the standards of a fair and objective review.

Copyright (c) 2017 Jacobs, Moshabela, Maswenyeho, Lambo and Michelo. This is an open-access article distributed under the terms of the Creative Commons Attribution License (CC BY). The use, distribution or reproduction in other forums is permitted, provided the original author(s) or licensor are credited and that the original publication in this journal is cited, in accordance with accepted academic practice. No use, distribution or reproduction is permitted which does not comply with these terms. 